\title{
Interfaces and defect composition at the near-atomic scale through atom probe tomography investigations
}

\author{
Baptiste Gault, ${ }^{\text {a),b) }}$ Andrew J. Breen, Yanhong Chang, Junyang He, Eric A. Jägle, Paraskevas Kontis, \\ Philipp Kürnsteiner, Alisson Kwiatkowski da Silva, Surendra Kumar Makineni, Isabelle Mouton, \\ Zirong Peng, Dirk Ponge, Torsten Schwarz, Leigh T. Stephenson, Agnieszka Szczepaniak, Huan Zhao, \\ and Dierk Raabe \\ Department of Microstructure Physics and Alloys Design, Max-Planck-Institut für Eisenforschung GmbH, \\ Düsseldorf 40237, Germany
}

(Received 24 May 2018; accepted 18 September 2018)

\begin{abstract}
Atom probe tomography (APT) is rising in influence across many parts of materials science and engineering thanks to its unique combination of highly sensitive composition measurement and three-dimensional microstructural characterization. In this invited article, we have selected a few recent applications that showcase the unique capacity of APT to measure the local composition at structural defects. Whether we consider dislocations, stacking faults, or grain boundary, the detailed compositional measurements tend to indicate specific partitioning behaviors for the different solutes in both complex engineering and model alloys we investigated.
\end{abstract}

\section{INTRODUCTION}

Field-ion-based techniques were initially developed for studying surfaces ${ }^{1,2}$ : The field ion microscope (FIM) reveals the structure of a material with atomic-scale resolution, ${ }^{3}$ at least in some parts of the image, while the implementation of a time-of-flight spectrometer onto a FIM, which is the atom probe, targeted the elemental identification of atoms images at the surface. ${ }^{4}$ The level of detail of the intimate structure of crystalline defects, being grain boundaries ${ }^{5}$ or dislocations, ${ }^{6}$ brought by FIM was astonishing, and the technique is unrivalled when it comes to observing individual vacancies. ${ }^{7,8}$ FIM provides three-dimensional information: the two-dimensions are provided by the projected image of the surface formed by the ionization of the imaging gas atoms, while the third dimension arises from the possibility to sequentially remove atoms from the specimen itself by field evaporation. ${ }^{8-13}$

The modern declination of FIM and atom probe techniques is sometimes referred to as atom probe microscopy. ${ }^{14,15}$ Atom probe tomography (APT) is now vastly dominating the field. APT is known for its capacity to map the local composition within a material with sub-nanometer resolution in three dimensions. ${ }^{16}$ State-of-the-art instruments ${ }^{17}$ use delay-line detectors combined with microchannel plates $^{18,19}$ for converting the impact of the incoming ion into a cloud of electrons that gets amplified to become detectable. These MCPs have a detection

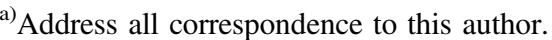

e-mail: b.gault@mpie.de,b.gault@imperial.ac.uk

${ }^{b)}$ Currently also at Department of Materials, Imperial College

London, United Kingdom.

DOI: $10.1557 / j m r .2018 .375$
}

efficiency limited by their open area to approx. $80 \%$ on state-of-the-art instruments. APT is primarily a massspectrometry technique, albeit with an unparalleled spatial resolution. ${ }^{20-24}$ Limited detection efficiency along with aberrations in the trajectories of the ions emitted from the surface dramatically affects the spatial resolution of $\mathrm{APT}^{20,25,26}$ and prevent the instrument to attain true atomic resolution; however, it reveals precise compositional information in three-dimensions that FIM could not provide. APT data, however, still often contains partial structural information that can be exploited to complement the microstructural and compositional information provided by the technique. ${ }^{27,28}$ Significant effort arose in the past decade to retrieve, extract, and make use of this structural information when available, to bring more insights into the complex structure-defects-composition interplay that, in combination, rules the physical properties of materials. ${ }^{29-33}$

The segregation of solutes to defects by APT has long been studied. Some of the most seminal work in the APT community was focused on these aspects, in intermetallics, ${ }^{34,35}$ steel, ${ }^{36}$ superalloys, ${ }^{37,38}$ and in semiconductors. ${ }^{39-42}$ In this invited feature article, we will showcase a few recent applications of APT from within our group at the Max-Planck-Institut für Eisenforschung that aimed to measure the local composition at specific structural defects, to explain fundamental aspects of phase formation and transformation or deformation mechanisms.

\section{EXPERIMENTAL}

Specimens for these studies were prepared by using a dual beam scanning electron microscope combined with a focused ion beam (SEM/FIB) following the protocol 
outlined in Thompson et al. ${ }^{43}$ A variety of samples will be discussed herein and some details on each material will be given in the following respective sections. Samples were first polished to a mirror finish, so as to make them suitable for high-end SEM imaging and analysis, including electron-backscattered diffraction (EBSD) and controlled electron-channeling contrast imaging (cECCI). Three different SEM/FIB equipped with a micromanipulator and a gas-injection-system were used to prepare the specimens presented herein: two FEI Helios 600 and 600i and a FEI Helios Plasma FIB (FEI, Eindhoven, The Netherlands). In the former two, the ions used for the FIB are Ga ions produced by a liquid-metal ion source, while for the latter, the FIB operates with $\mathrm{Xe}$ ions generated by a radio frequency plasma source. Specimen preparation for APT has seldom been reported with such instruments, except by Estivil et al. ${ }^{44}$ who used a single-beam plasma-based FIB in their study of Si-based materials. The atom probe data presented here were acquired on various commercial Cameca LEAP instruments (CAMECA, Gennevilliers, France): a LEAP $3000 \mathrm{HR}$, a LEAP $5000 \mathrm{XS}$, and a LEAP 5000 XR. The running conditions will be specified below for each case study.

\section{RESULTS AND DISCUSSION}

\section{A. Al-alloys}

APT brought numerous insights into the early stages of precipitation in Al-alloys. ${ }^{45,46}$ However, only little has been done with respect to segregation to boundaries and lattice defects. ${ }^{47}$ With APT's limited capacity for detecting lattice defects, a strategy has sometimes been pursued to use a foreign atom with a high tendency for segregation to mark defects for analysis. For instance, the use of $\mathrm{Ga}$ to highlight the presence of defect has been proposed on multiple occasions. $^{33,48}$ This works particularly well for Al-based alloys because of the very fast diffusion of $\mathrm{Ga}$ in $\mathrm{Al}$.

A sample was produced using laser metal deposition $(\mathrm{LMD})^{49,50}$ from an $\mathrm{Al}_{1.0} \mathrm{Sc}_{0.6} \mathrm{Zr}$ (wt $\%$ ) powder using fiber coupled diode laser system with a wavelength of $976 \mathrm{~nm}$ and a beam diameter of $1.8 \mathrm{~mm}$. Ar was used as a carrier and shielding gas. A track offset of $1000 \mu \mathrm{m}$, a height offset of $750 \mu \mathrm{m}$, a laser power of $1800 \mathrm{~W}$, and a deposition speed of $600 \mathrm{~mm} / \mathrm{min}$ were used. Since a Sc content of $1 \mathrm{wt} \%$ is hypereutectic, upon cooling $\mathrm{Al}_{3}(\mathrm{Sc}$,$\mathrm{Zr}$ ) particles can form as primary precipitates directly from the meltpool during the additive manufacturing process. Due to the low lattice mismatch of the $\mathrm{Al}_{3}(\mathrm{Sc}, \mathrm{Zr})$ precipitates and the $\mathrm{Al}$ matrix of below $1 \%,{ }^{51}$ these primary precipitates act as efficient nuclei for the solidifying $\mathrm{Al}$ matrix as the temperature drops. The lattice misfit along the arising interface is compensated by misfit dislocations leading to a semicoherent interface of this primary precipitate with the $\mathrm{Al}$ matrix.
The APT specimen was prepared by the commonly used lift-out protocol described, e.g., in Ref. 43 using a FEI Helios NanoLab 600i focused ion beam/scanning electron microscope (FIB/SEM) dual beam device. The tip was placed on a silicon microtip coupon and sharpened by means of annular milling patterns at $30 \mathrm{kV}$ acceleration voltage with ion currents ranging from $0.23 \mathrm{nA}$ to $40 \mathrm{pA}$. A final low $\mathrm{kV}$ cleaning mill at $5 \mathrm{kV}$ acceleration voltage and $40 \mathrm{pA}$ was applied. APT experiments were performed in a Cameca LEAP 5000 XS at a base temperature of $60 \mathrm{~K}$, a pressure of less than $10^{-10}$ mbar in the laser mode using a pulse energy of $0.1 \mathrm{~nJ}$, a pulse frequency of $833 \mathrm{kHz}$, and a detection rate of $2 \%$. 3D reconstruction was conducted using commercial software IVAS version 3.6.14. Voxel-based analysis such as isosurfaces was performed with a grid spacing of $1 \mathrm{~nm}$, applying a delocalization of $3 \mathrm{~nm}$.

Figure 1(a) shows the elemental distribution obtained from the APT analysis of a specimen that contains a phase boundary between a primary $\mathrm{Al}_{3}(\mathrm{Sc}, \mathrm{Zr})$ precipitate and
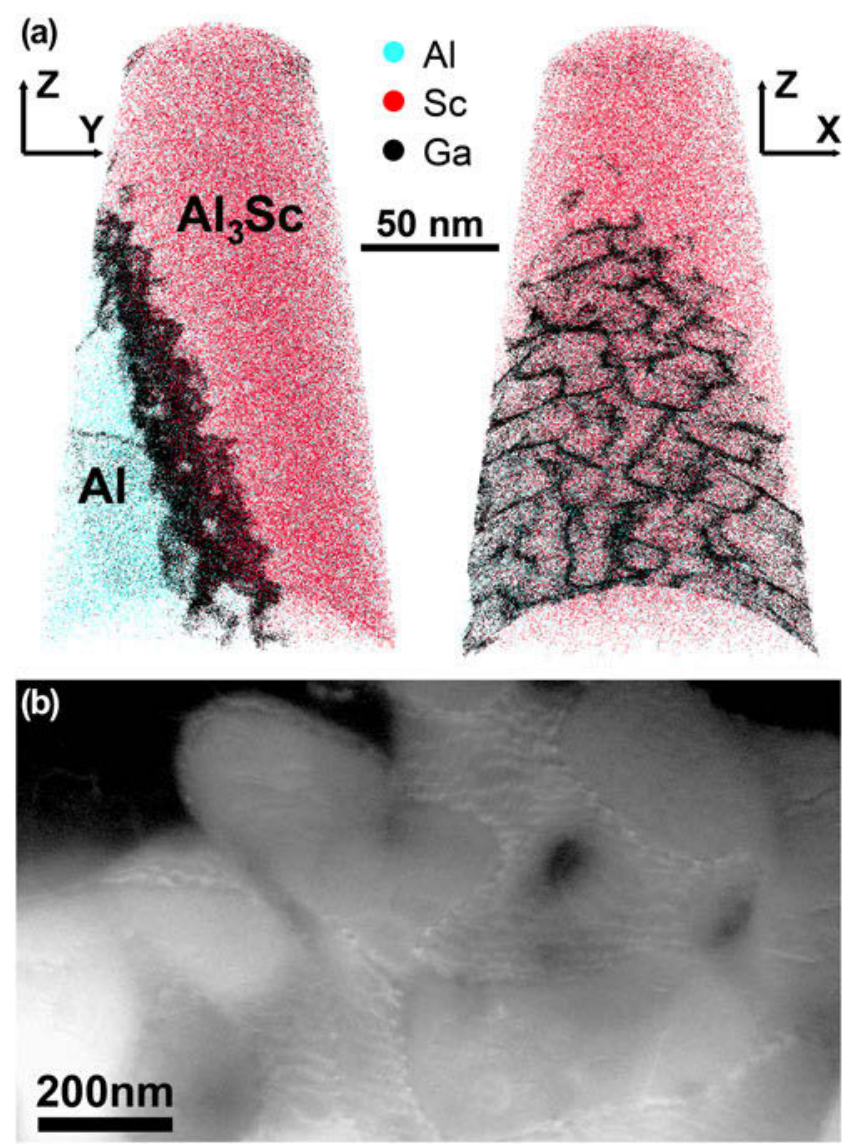

FIG. 1. (a) An APT measurement of a tip that contains the phase boundary of a primary $\mathrm{Al}_{3}(\mathrm{Sc}, \mathrm{Zr})$ precipitate and the $\mathrm{Al}$ matrix. $0.05 \%$ of $\mathrm{Al}$ atoms, $2 \%$ of $\mathrm{Sc}$ atoms, and $100 \%$ of $\mathrm{Ga}$ atoms are shown. Misfit dislocations along the interface are highly enriched in $\mathrm{Ga}$ which stems from FIB sample preparation; (b) an ECCI micrograph of the same type of misfit dislocation network. 

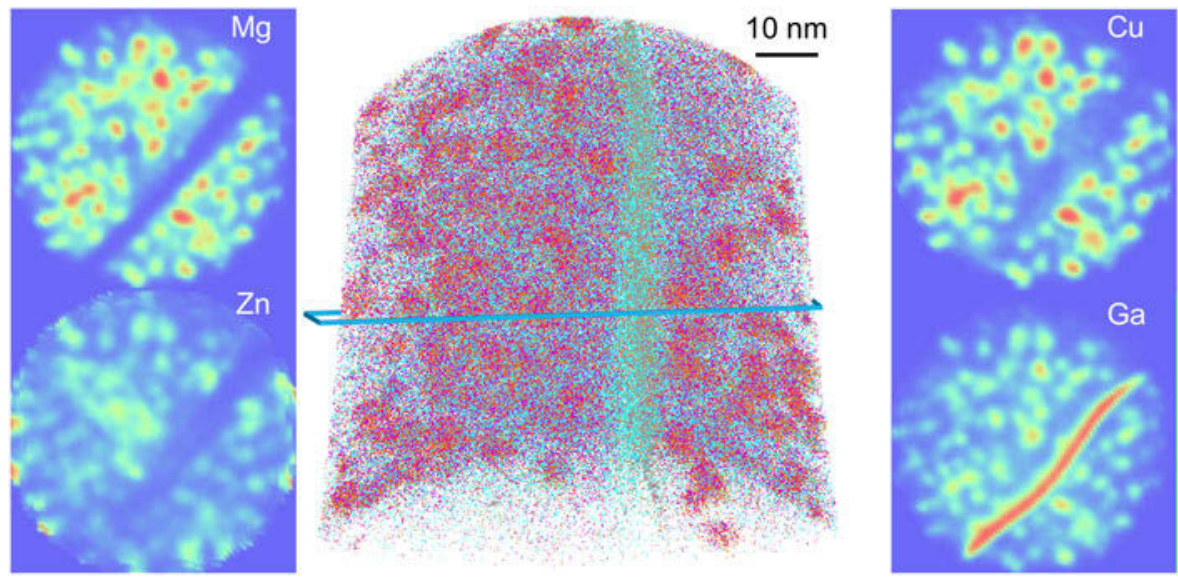

FIG. 2. APT reconstruction containing a high-angle grain boundary from a specimen prepared in a model $\mathrm{Al}-\mathrm{Mg}-\mathrm{Zn}-\mathrm{Cu}$ alloy with a $\mathrm{Ga}-\mathrm{FIB}$, showing the 2D compositional maps for the main three solutes and of $\mathrm{Ga}$, highlighting the strong segregation of Ga to the boundary and the precipitate-matrix interfaces.

the Al matrix. Figure 1(b) is an electron channeling contrast image collected in the scanning electron microscope that shows strong atomic-number contrast in addition to the channeling contrast. The Ga distribution in the corresponding atom map forms a complex pattern that can likely be attributed to the presence of a high density of interfacial dislocations where Ga can segregate. This network of misfit dislocations is highly decorated by Ga atoms after FIB tip preparation. Additional to the misfit dislocation network, two single dislocations leading into the $\mathrm{Al}$ matrix are enriched in $\mathrm{Ga}$ as well. The Ga content in the misfit dislocations can reach up to 25 at.\%; in the single dislocation, it reaches up to 11 at.\%. The effect of decoration of defects with Ga is 2-fold: on the one hand side, it enables observation of dislocations and dislocation-based phenomena such as, e.g., heterogeneous nucleation in APT datasets that might otherwise be overlooked if dislocations are not decorated by any alloying element. On the other hand, enrichment of Ga up to 25 at.\% will clearly have an influence on the interface and bias any quantification of elemental segregation on the interface.

The local composition of these specific features does not otherwise reveal any specific segregation in this $\mathrm{Al}-\mathrm{Sc}-\mathrm{Zr}$ alloy, which makes them extremely difficult or impossible to visualise. The effect of $\mathrm{Ga}$ has on the local solute distribution is also unknown and difficult to quantify. This can become problematic for instance in a case where segregation is expected. Figure 2 shows the tomographic reconstruction from an analysis of a specimen containing a high-angle grain boundary in a model $\mathrm{Al}-\mathrm{Mg}-\mathrm{Zn}-\mathrm{Cu}$ alloy in the peak aged state, i.e., after $24 \mathrm{~h}$ at $120^{\circ} \mathrm{C}$ aging following solution heat treatment at $475{ }^{\circ} \mathrm{C}$ for an hour and water quenching. The specimen was prepared via sitespecific lift-out on a Ga-FIB. In Fig. 2, the Guinier-Preston (GP) zones in the bulk of the grains are clearly visible, as well as the grain boundary itself that shows a slight depletion of all solutes but a very strong segregation of $\mathrm{Ga}$. The main unknown which remains is how the presence of $\mathrm{Ga}$ to the defect may have perturbed the segregation behavior of other solutes. The strong attraction of Ga to defects, specifically in Al-alloys, brings into question the validity of quantification of the segregation to crystalline defects in this alloy family, which may explain why the literature on this topic is rather sparse. ${ }^{33,47,52}$

The use of alternative ion milling sources, particularly $\mathrm{Xe}$, has recently been of significant scientific interest. A pure-Al sample for scanning electron microscopy was mechanically polished to a mirror finish, and subsequently a coarse electron-backscattered electron diffraction scan was performed to identify a random highangle boundary, as shown in Fig. 3(a). The selected grain boundary has a minimum misorientation of approx. $49^{\circ}$ about the $\langle 24215\rangle$ axis. We then used the protocol from Ref. 43 for in situ lift-out but simply used a Xe-plasma in a FEI Helios PFIB to perform target preparation of a random high-angle grain boundary (RHAGB), with the main cuts and sharpening steps performed at $30 \mathrm{kV}$ acceleration voltage, followed by a cleaning step at $5 \mathrm{kV}$. Figure 3(b) is the tomographic reconstruction resulting from the corresponding analysis. Only a fraction of the $\mathrm{Al}$ ions is shown, but all the ions detected in ranges corresponding to the mass-tocharge ratios of Xe are displayed (red dots). The grain boundary is visible as a region of slightly higher point density within the tomogram. A composition profile calculated in a $10 \mathrm{~nm}$-diameter cylinder across the boundary and is plotted in Fig. 3(c). The number of ions within each bin of the profile is also plotted, in red, as a function of the distance along the cylinder. The peak in this profile corresponds to the position of the grain boundary. Only a small amount of $\mathrm{Xe}$ is detected in the profile, with no noticeable peak at the location of the grain boundary. This opens the 

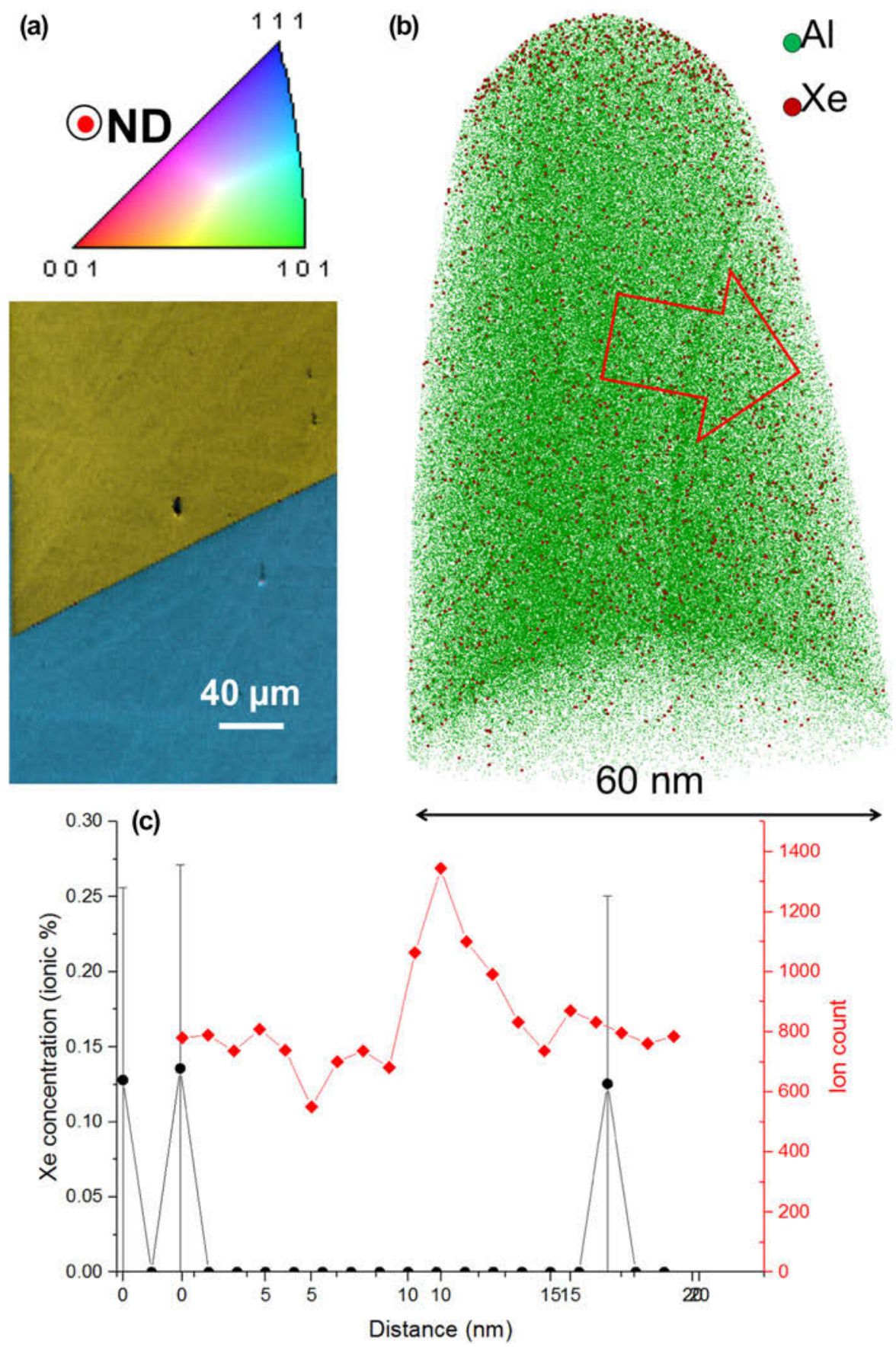

FIG. 3. (a) EBSD coloured orientation and image quality maps combined around the selected grain boundary in pure-Al; (b) tomographic reconstruction from the corresponding analysis; (c) Xe-composition profile calculated along the red arrow in (b) and local point density along the cylinder used to calculate the profile.

opportunity for more accurate analysis of crystalline defects in Al-based alloys.

\section{B. Line defects near oxidized carbides in $\mathrm{Ni}$-based superalloys}

We have also turned our attention to deformed microstructures in Ni-based superalloys exhibiting a $\gamma / \gamma^{\prime}$ microstructure. ${ }^{53-55}$ In a recent article, we reported on the strong segregation of $\gamma$ stabilizing elements, primarily $\mathrm{Cr}$ and $\mathrm{Co}$ onto a complex network of linear features appearing within $\gamma^{\prime}$ precipitates in various alloys, incl. IN782 and MC2. For those samples, the specimens had been prepared in regions of the deformed microstructure imaged by cECCI that showed a very high dislocation density. The features observed in these tomographic 
reconstructions were hence assumed to be dislocations that are decorated by solutes, similar to those reported by Kuzmina et al. in their correlative TEM/APT investigation of confined transformations in the $\mathrm{Fe}-\mathrm{Mn}$ system. ${ }^{56}$ Composition profiles though the features revealed either single peaks of segregation corresponding to a dislocation or double peaks that might be the sign of two partial dislocations surrounding an extended defect. Interestingly, the segregation to the front and trailing partials, which are of different kinds, bear different amounts of solutes.

This work shed light on a long-standing question of whether pipe diffusion can take place within superalloys during high temperature deformation, e.g., creep, and, more importantly perhaps, which elements are subject to pipe diffusion. Pipe diffusion relates to an enhanced diffusivity via processes occurring in the core of individual dislocations or arrays of dislocations. ${ }^{57,58}$ Pipe diffusion is expected to accelerate the transport of elements $^{58,59}$ and hence play a major role in the high temperature creep that leads to the rafting of the $\gamma^{\prime}$ precipitates and their progressive dissolution. ${ }^{60,61}$ Here we provided quantitative evidence that $\mathrm{Cr}$ and $\mathrm{Co}$, two $\gamma$ stabilizers exhibited a strong tendency to be attracted, and to segregate to dislocations. A likely possibility is that these solutes are carried along as the dislocations move through the $\gamma / \gamma^{\prime}$ interface. Indeed, no radial gradient of solutes was observed near the dislocations, which would result from the diffusion of solutes toward the dislocations during cooling for instance.

In addition, the high concentration of defects in some regions of the microstructure likely assists mass transport significantly. Figure 4 summarizes the structural changes revealed by APT in the surroundings of a carbide that was oxidized during static exposure to air at $750{ }^{\circ} \mathrm{C}$ for $50 \mathrm{~h}$ of a fully heat-treated polycrystalline superalloy IN792. The carbide has turned into a complex oxide, dislocations carrying $\mathrm{Cr}$ and $\mathrm{Co}$ are observed in the original grains, a number of small recrystallized grains are observed in the vicinity of the oxidized carbide, and these grains are a single phase with a composition that shows a severe depletion of $\mathrm{Cr}$ and, to a lesser extent $\mathrm{Co}$, leading to a solid solution $\gamma_{R}$ with a previously unreported composition. We proposed a mechanism to rationalize these observations. The oxidation of the Tarich carbide leads to a strong volume expansion, expected

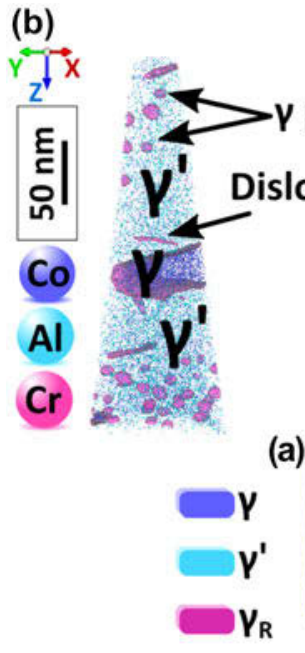

(d)
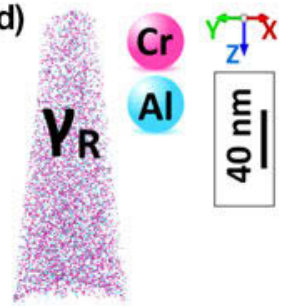
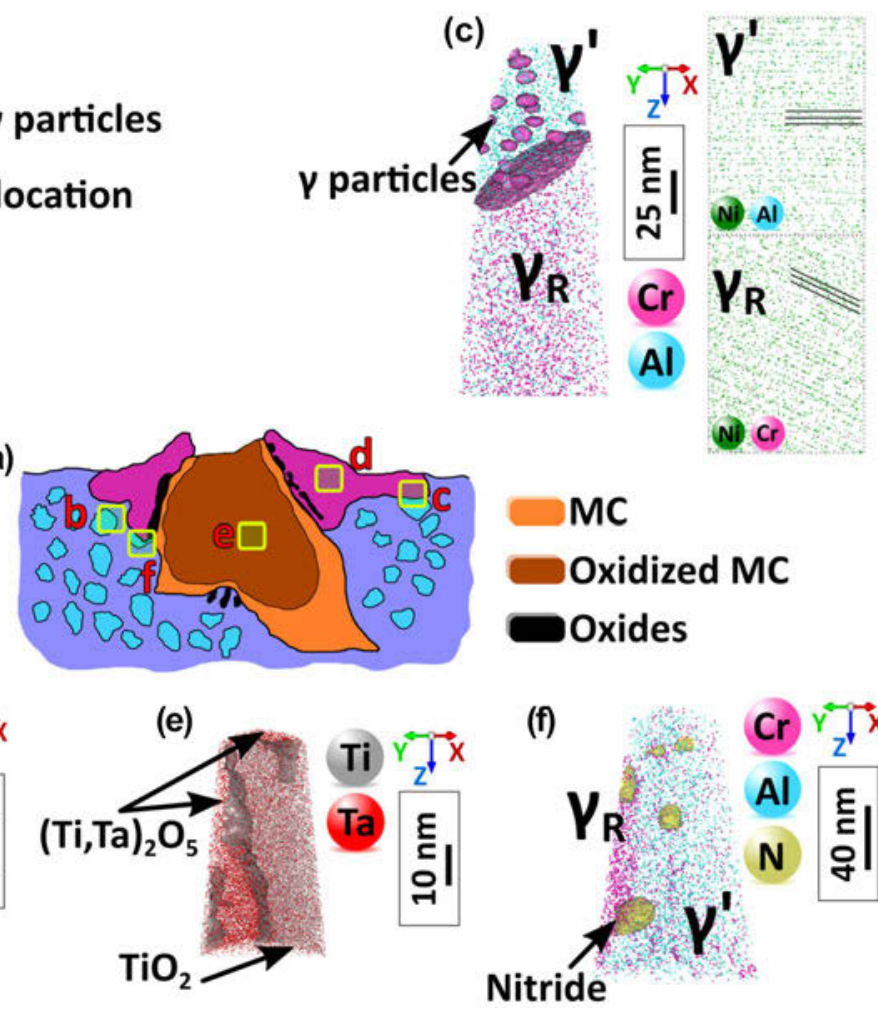

FIG. 4. (a) Schematic illustration of the oxidized carbide. (b) APT analysis in the $\gamma / \gamma^{\prime}$ region showing dislocations and $\gamma$ precipitates within the $\gamma^{\prime}$ precipitate. (c) APT reconstruction showing $\gamma^{\prime} / \gamma \mathrm{R}$ interface, $\gamma$ precipitates within $\gamma^{\prime}$, and two sets of crystallographic planes from the same crystallographic direction from each side of the interphase interface. (d) APT reconstruction within the $\gamma \mathrm{R}$ solid solution in the recrystallized grain. (e) APT reconstruction from the oxidized MC carbide showing two different oxide compositions $\mathrm{TiO}_{2} /(\mathrm{Ti} \text {, } \mathrm{Ta})_{2} \mathrm{O}_{5}$. (f) APT reconstruction showing a $\gamma \mathrm{R} / \gamma^{\prime}$ interface and small nitrides at the $\gamma \mathrm{R} / \gamma^{\prime}$ interface and within the $\gamma^{\prime}$ precipitate, indicative of the penetration of $\mathrm{N}$ within the structure, also likely assisted by the deformation process (Reprinted with permission from Ref. 54.). 
to be approximately a factor of $2,{ }^{62}$ which causes plastic deformation of the surrounding microstructure. By carrying solutes, potentially over large distances, this deformation can explain the local destabilization of the equilibrium and the subsequent dissolution of the main strengthening phase present in the original $\gamma / \gamma^{\prime}$ microstructure. We observed this process in a range of different alloys and for multiple sources of deformation and hence believe this process to be of general nature. The weakening of the structure close to the oxidized carbide can therefore be directly attributed to the local deformation combined with the mass transport assisted by the high density of dislocations that carry their own solute atmospheres and facilitate pipe diffusion. This weakening of the structure will impact the crack initiation and lifetime of engineering parts in service.

\section{Segregation to stacking faults}

We recently devoted significant effort to reveal and quantify segregation to stacking faults formed during creep deformation of $\gamma-\gamma^{\prime}$ Co-based superalloys. These alloys show very high creep resistance and are being developed for application as the blade material in hightemperature gas turbine. These alloys are made of a disordered solid solution matrix with face-centered cubic (fcc) crystal structure ( $\gamma$ phase) and ordered precipitates with a $\mathrm{L1}_{2}$ crystal structure ( $\gamma^{\prime}$ phase). Depending on the temperature and the external stress, the deformation mechanism in the microstructure results in the shearing of $\gamma^{\prime}$ either by the creation of antiphase boundaries, stacking faults, and/or micro-twinning. In the past decade, numerous articles reported solute segregations to these defects, in particular to stacking faults. ${ }^{63,64}$ It was then proposed that the rate limiting steps for creep deformation are related to local solute diffusivity in the vicinity of these defects. Here, as detailed in Fig. 5(a), we used electron-channeling contrast imaging in the scanning electron microscope ${ }^{65}$ to guide the selection of a region-of-interest in the microstructure to analyze a single stacking-fault by APT. In a second step, highresolution scanning-transmission electron microscopy was used to confirm the presence and characterize the nature of the fault, as shown in Fig. 5(b). APT provides the full compositional field, and, in Fig. 5(c) are plotted the composition profiles through the stacking fault, the leading partial dislocation and along the stacking fault. These profiles reveal significant variations across the fault, with a clear segregation of $\mathrm{Co}$ and $\mathrm{W}$ and a depletion of Al. This can be explained by the local change from a face-centered cubic $\mathrm{Ll}_{2}$ ordered structure to hexagonal-close packed $\mathrm{DO}_{19}$ ordered structure, which is the structure of the stable $\mathrm{Co}_{3} \mathrm{~W}$ phase. The leading partial dislocation that creates the fault in the ordered precipitate sees segregation of $\mathrm{Cr}$ and $\mathrm{Co}$, which are both partitioned to the $\gamma$ matrix, similarly what was observed in the Ni-based systems, as well as a depletion of $\mathrm{Al}$. Finally, we could show evidence of a pile-up of $\mathrm{Al}$ ahead of the fault that had previously not been reported. ${ }^{66,67}$ The gradients observed along the fault suggests the integration of $\mathrm{W}$ and $\mathrm{Ta}$ and subsequent diffusion along the fault, through the partial dislocation, as schematically depicted in Fig. 5(d). This change of composition ahead of the partial is expected to affect the pace at which the partial can move through the ordered precipitate and hence the overall mechanical behavior of the material under load.

\section{Segregation in CIGS}

Solar cells based on polycrystalline $\mathrm{CuInGaSe}_{2}$ thin films have attracted considerable attention in the past few years for their high conversion efficiency. $\mathrm{Cu}(\mathrm{In}$,$\mathrm{Ga})(\mathrm{S}, \mathrm{Se})_{2}$-based thin-film solar cells achieve power conversion efficiencies of up to $22.9 \%{ }^{68}$ despite the polycrystalline nature of the absorber material. Hence, it is essential to link the structural and chemical properties with the optoelectronic properties of defects such as grain boundaries. ${ }^{41}$ Figures 6(a)-6(c) show a correlative transmission Kikuchi diffraction (TKD)-APT study of a RHAGB from a Cu(In,Ga) $\mathrm{Se}_{2}$-based absorber. ${ }^{69}$ Beside the chemical fluctuations of the matrix elements, we detect co-segregation of the $\mathrm{Na}$ and $\mathrm{K}$ at the grain boundary, as shown in Figs. 6(b) and 6(c), where the Gibbs excess values are $3.2 \mathrm{at} / \mathrm{nm}^{2}$ and $0.4 \mathrm{at} / \mathrm{nm}^{2}$ for $\mathrm{Na}$ and $\mathrm{K}$, respectively. This is reflected in the concentration profile across the RHAGB in Fig. 6(d) that exhibits a clear In and Se enrichment as well as $\mathrm{Cu}$ depletion. In some cases, we also observe slight $\mathrm{Ga}$ depletion. Here, the alkali metals are out-diffusing from the soda-lime glass substrate, which contains $\mathrm{Na}_{2} \mathrm{O}$ and $\mathrm{K}_{2} \mathrm{O}$. At twin boundaries, we do not detect variations of the matrix elements and segregation phenomena. The atomic redistribution, more precisely the $\mathrm{Cu}$ depletion, at the RHAGB indicates a downward band bending at the $\mathrm{GB}$, which acts as a neutral hole barrier. ${ }^{70}$ Furthermore, the formation of compensating $\operatorname{In}_{\mathrm{Cu}}{ }^{2+}$ donors might be reduced by the segregation of $\mathrm{Na}$ and $\mathrm{K}$, which can form charge neutral $\mathrm{Na}_{\mathrm{Cu}}{ }^{0}$ and $\mathrm{K}_{\mathrm{Cu}}{ }^{0}$ point defects. Latter ones do not create any defect level within the band gap according to DFT calculations. ${ }^{71}$ Indeed, RHAGBs exhibit enhanced nonradiative recombination compared to twin boundaries, but which are still $<1 \times 10^{4} \mathrm{~cm} / \mathrm{s}^{70}$ The reason for this electrical passivation might be the abovementioned atomic redistribution and segregation of alkali metals.

\section{E. Phase nucleation at crystalline defects}

A detailed study of the segregation of Mn to linear defects in a model Fe-9Mn binary alloy by a combination 

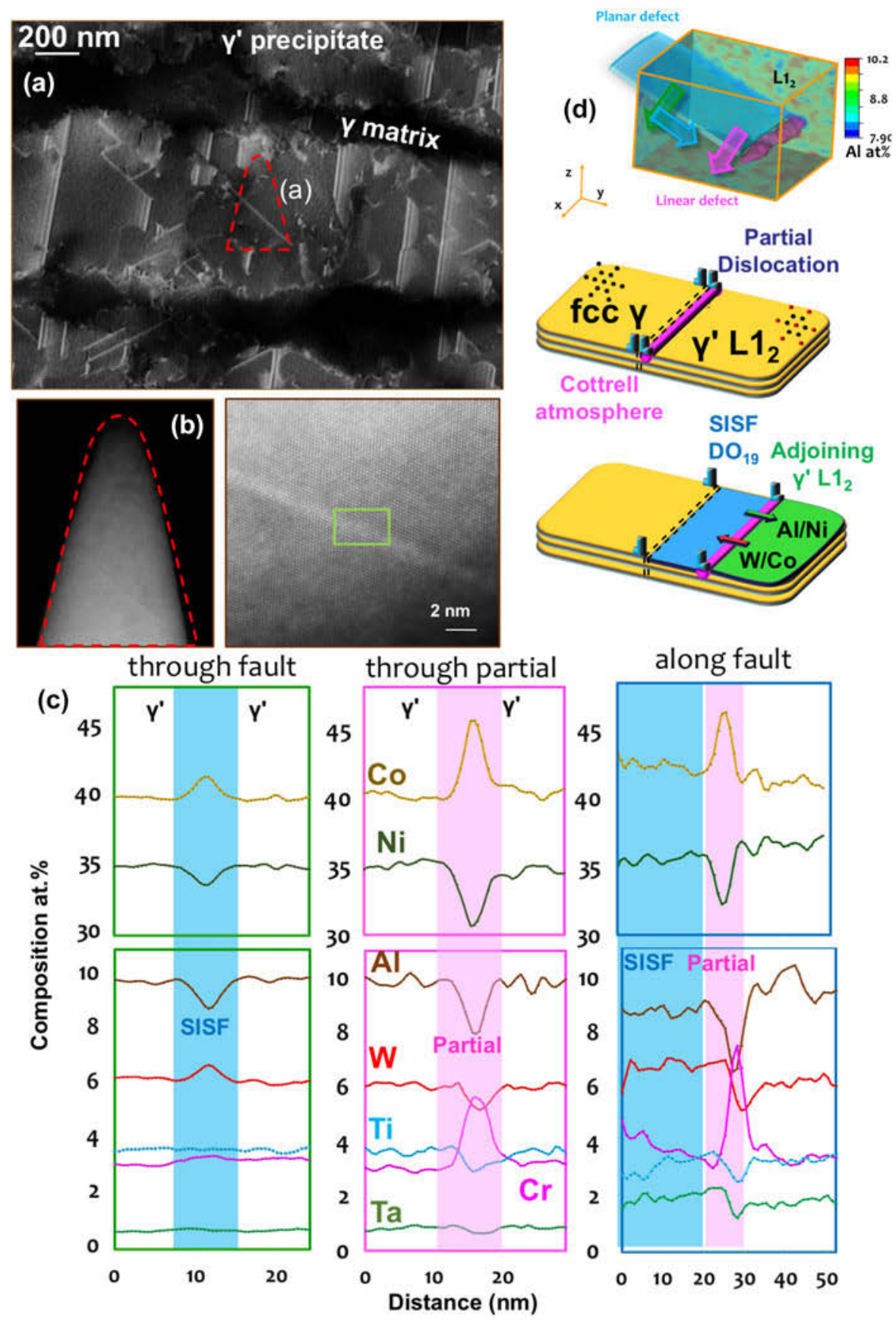

FIG. 5. (a) ECCI of a crept CoNi-based superalloy taken near the [110] direction showing the rafted $\gamma^{\prime}$ parallel to the tensile loading direction. (b) Low- and high-magnification scanning transmission electron micrographs (high-angle annular dark field) of the APT specimen along the [110] zone direction showing planar stacking fault in bright contrast. (c) Composition profiles across stacking fault, leading partial dislocation, and along the stacking fault plane. (d) Full three-dimensional compositional field of $\mathrm{Al}$ and schematic illustration of the diffusional processes taking place (Reprinted with permission from Ref. 66.).

of APT and transmission electron microscopy led to the possible detection of confined phases, nucleated at dislocations that are not isostructural with the host matrix. $^{56,73}$ These are akin to the concept of complexions, a term that describes the interfacial state in local equilibrium with its abutting phase $(\mathrm{s})^{74,75}$ One of the most interesting aspects of this study is the reasoning that there is a strong interplay between the local structure and the local composition of a specific microstructural feature. Further analyses of crystalline defects in this same system led us to further highlight the specific behavior of these confined regions, providing evidence of confined spinodal decomposition of the solutes that are adsorbed to the grain boundary. 
This is highlighted in Fig. 7 that details the information obtained from a single dataset. In Fig. 7(a), the structural information extracted from the partial crystallographic information available within the detector hit maps shown in Fig. 7(a) allow for full misorientation determination. $^{27,29,33}$ Figure $7(\mathrm{~b})$ is a close-up on the
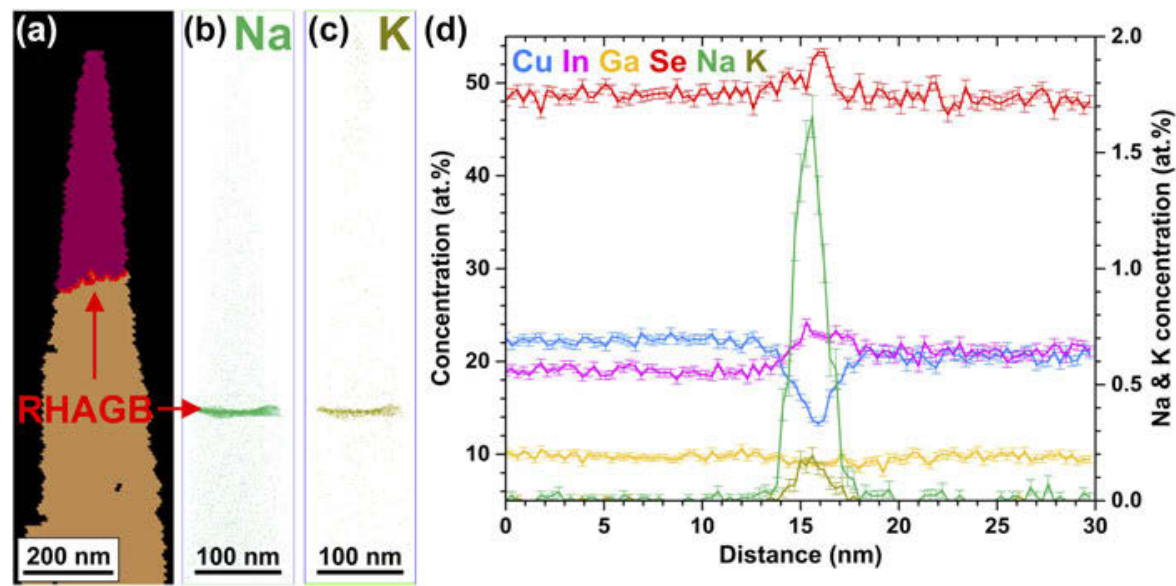

FIG. 6. (a) TKD measurement of an APT specimen from a $\mathrm{Cu}(\mathrm{In}, \mathrm{Ga}) \mathrm{Se}_{2}$ thin-film. The red line marks a RHAGB. (b) and (c) Reconstructed APT dataset showing co-segregation of $\mathrm{Na}$ and $\mathrm{K}$ atoms at the RHAGB. (d) $1 \mathrm{D}$ concentration profile across the RHAGB showing an atomic redistribution (Reprinted with permission from Ref. 69.).
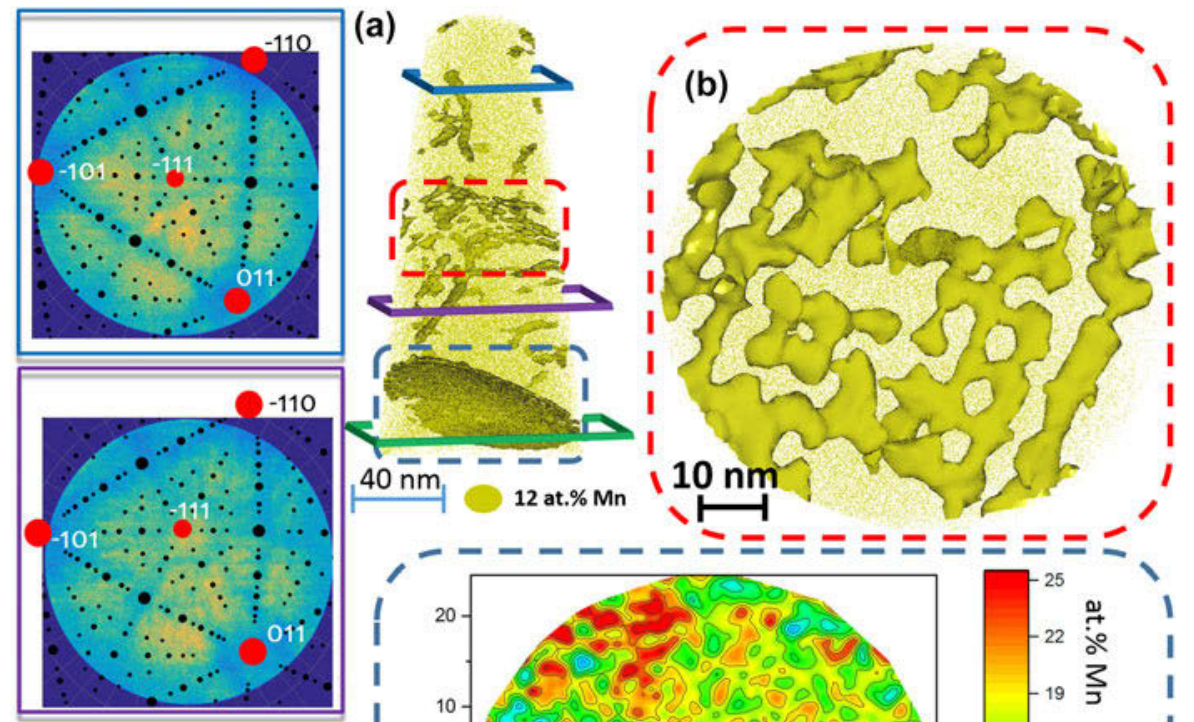

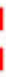
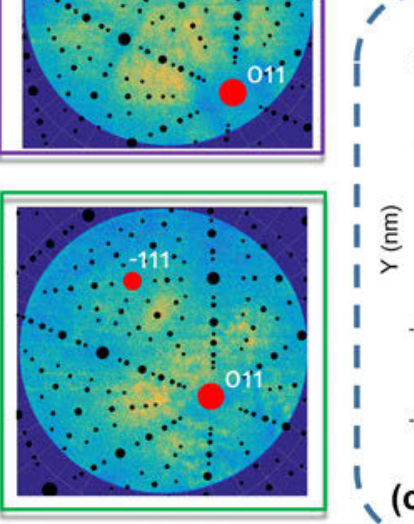

(c)

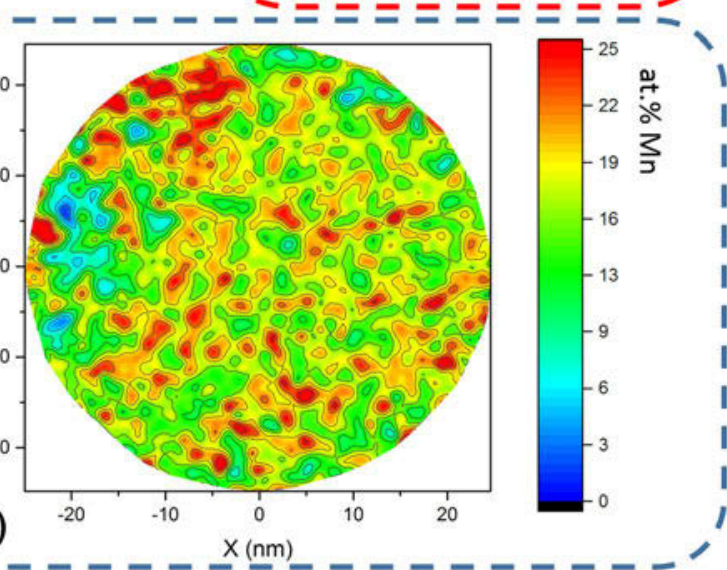

FIG. 7. APT analysis of a grain boundary decorated with $\mathrm{Mn}$ after $6 \mathrm{~h}$ at $450{ }^{\circ} \mathrm{C}$. (a) The 12.5 at. $\%$ Mn iso-concentration surfaces $(12.5$ at. $\%$ Mn was chosen as a threshold value to highlight Mn-enriched regions). The detector map of the regions marked by the blue, purple, and green frames, respectively. The corresponding stereographic projections (black dots) after the identification of the main poles in the map (red dots) were superimposed. (b) Detail of the twisted low-angle grain boundary marked by the red dashed box in (a) as revealed by the iso-concentration surfaces. The grain boundary highlighted by the blue dashed box in (a) was exported and displayed in (c) using an in-plane concentration analysis inside the grain boundary plane (caption adapted and figure reproduced with authorization from Ref. 72, for which the content is covered by a CC-Attribution 4.0 licence authorizing reuse of content with modification). 


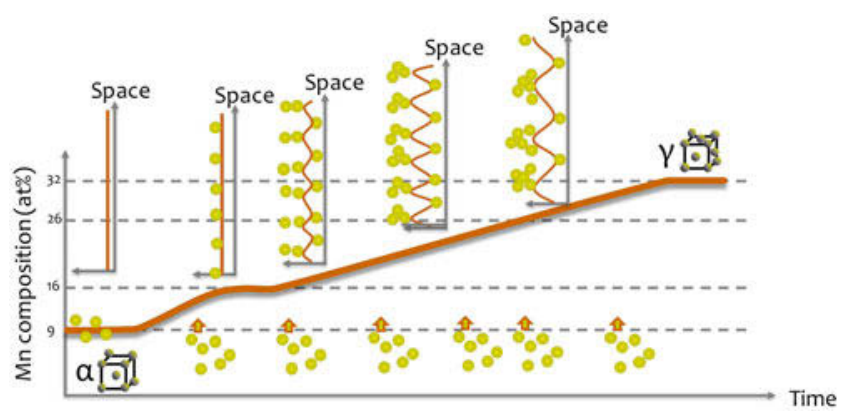

FIG. 8. Schematic view of the progressive evolution of the Mn segregation over time: as $\mathrm{Mn}$ segregates to the boundary, the composition reaches point at which spinodal fluctuations appear in space, as the maximum amplitude of the spinodal waves is reached, the wavelength of the fluctuations increases. low-angle grain boundary located in the central part of the dataset, which shows a clear pattern of decorated line defects along which composition fluctuates. Figure 7(c) is a two-dimensional composition map of the high-angle grain boundary, located toward the bottom of the dataset, and it shows clear compositional fluctuations.

At $450{ }^{\circ} \mathrm{C}$, a miscibility gap appears in the Fe-Mn phase diagram that can lead to a spinodal decomposition. ${ }^{72}$ As the local composition of a microstructural feature reaches a certain threshold composition, compositional fluctuations along the linear defects and planar defects can be interpreted as a confined spinodal fluctuations. Indeed, during aging at high temperature, solutes will tend to segregate to the defects to help lower the system's free (a)

(b)

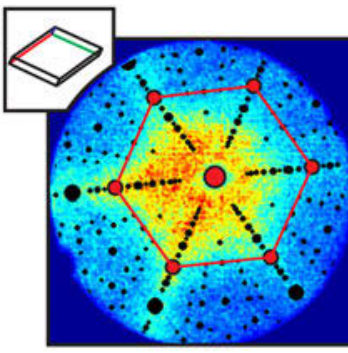

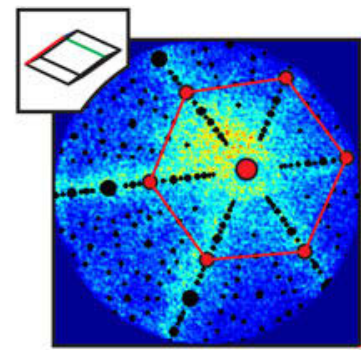

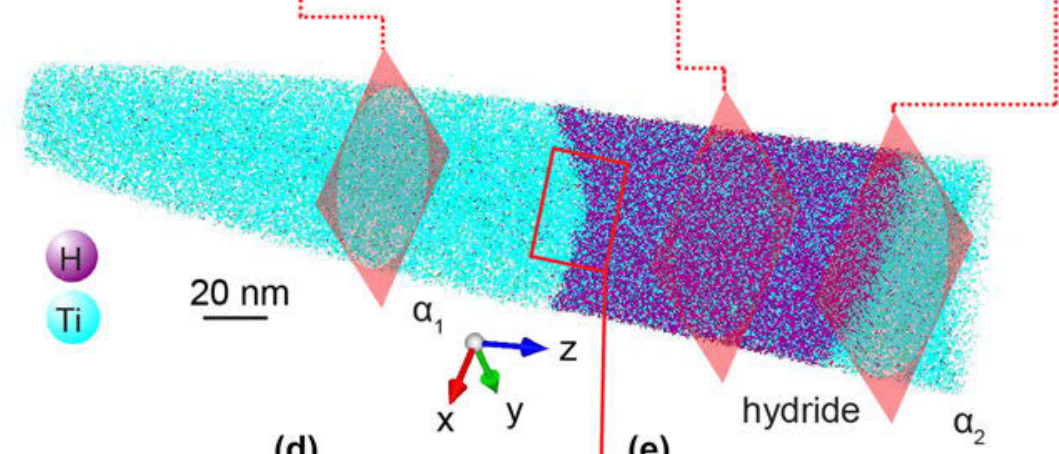

(c)

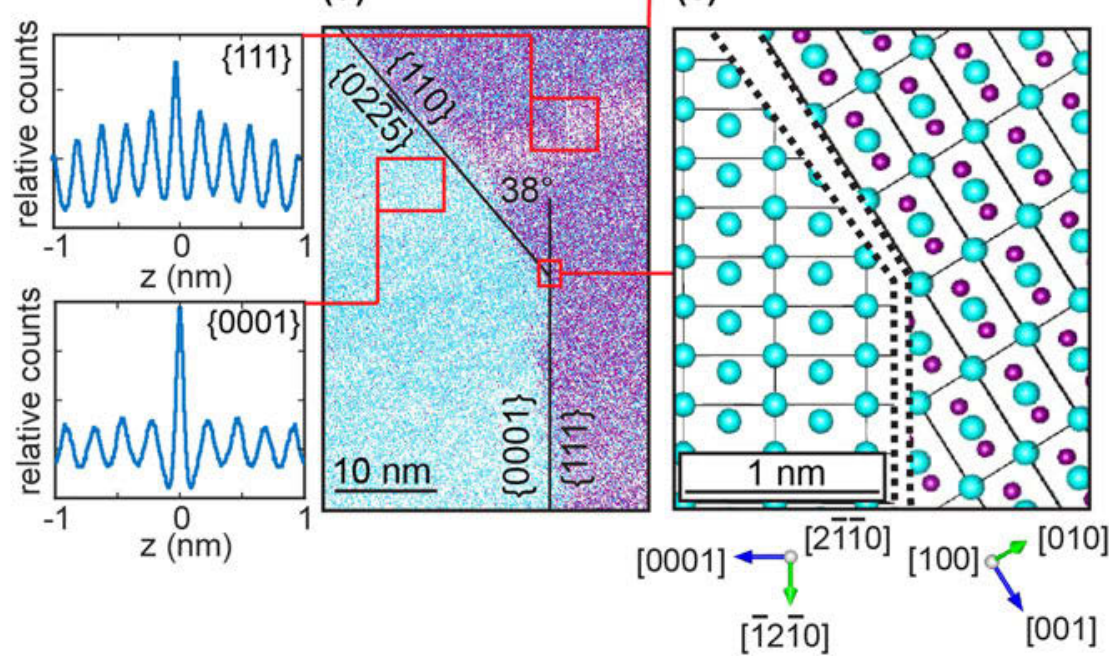

FIG. 9. Atom probe crystallography analysis of a hydride precipitated at a $\alpha$ low-angle grain boundary in Ti-2Fe: (a) patterns formed on the detector during the analysis exhibiting the typical symmetries from the local crystalline phase highlighted by the superimposed stereograms; (b) APT reconstruction and (c) spatial distribution maps revealing the presence of atomic planes in the tomographic reconstruction near the $\alpha$-Ti/ hydride interface shown in (d); (e) model of the faceted a/hydride (Reprinted with permission from Ref. 82.). 
energy, as the segregation keeps proceeding, the confined system at the defect will progressively reach the composition at which the miscibility gap appears in the $\mathrm{Fe}-\mathrm{Mn}$ system at the grain boundary. This triggers phase separation and compositional fluctuations appear. This is summarized schematically in Fig. 8. Such strong compositional variations within the grain boundary will greatly influence the succession of phase formations and hence development of the microstructure and we showed that these likely influence the nucleation of austenite in this specific alloy and that they could explain the mechanical properties of the alloy in the early stage of aging. ${ }^{76}$

\section{F. Heterogeneous nucleation of hydrides in titanium}

Titanium and its alloys are known for their high affinity for hydrogen and their tendency to form thermodynamically stable hydrides. ${ }^{77}$ Ti-hydrides are known to influence the brittle fracture of Ti-alloys during service. ${ }^{78,79}$ It was reported that the high susceptibility for hydride formation of $\mathrm{Ti}$ can lead to the formation of spurious hydrides during specimen preparation that affect the local microstructure before precise characterization is possible. ${ }^{80,81}$ We exploited the formation of hydrides, subsequent to focused-ion beam irradiation during specimen preparation, to investigate stable hydrides by APT. ${ }^{82}$ Commercially pure Ti and multiple alloy systems were investigated. Figure 9 shows a hydride that has nucleated in a binary $\mathrm{Ti}-2 \mathrm{Fe}$ alloy. Here again, atom probe crystallography analysis of the detector hit maps reveals key features. First, the hydride has formed at a grain boundary, as assessed by the shift in the position of the pole that exhibits a 6-fold symmetry corresponding to the $\{0002\}$ set of planes of the hexagonal-close-packed $\alpha$-Ti in Fig. 9(a). The orientation between the two grains changed by approximately $5.4^{\circ}$. Second, the region with high hydrogen composition, visible in Fig. 9(b), has transformed into a hydride, which is revealed by the change in the pole pattern in the detector hit map. A clear $\{111\}$ pole aligns with the $\{0002\}$ pole of the bottom grain. This observation is indicative of an orientation relationship that agrees with previous reports from transmission electron microscopy. ${ }^{77}$ The plane spacing was assessed by spatial distribution maps, ${ }^{32}$ displayed in Fig. 9(c), and the planes themselves are visualized in Fig. 9(d). A model of the interface is proposed in Fig. 9(e). This study allowed for quantification of the composition and interfacial segregation behavior of hydrides that have grown subsequently FIB-based sample preparation most likely via a heterogeneous nucleation process.

\section{SUMMARY}

Herein, we have reviewed the application of APT, in conjunction with electron microscopy-based techniques, to study the local composition of individual structural defects that differ from their surrounding due to segregation. These confined regions near or at defects exhibit their own partitioning behaviour and can be considered as separate confined phases or complexions (this is a terminology debate that falls outside the scope of the current article). APT is ideally suited to study segregation to crystalline defects and the unique insights brought by the application of the technique are critical to understand phenomena and processes at the nanoscale and hence predict the microstructural evolution during the lifetime of parts made from these typical engineering alloys.

\section{ACKNOWLEDGMENTS}

Uwe Tezins and Andreas Sturm are acknowledged for their constant support in running the atom probe facilities at MPIE. The BMBF is acknowledged for financial support to the UGSLIT project, which enabled the purchase of the PFIB and the funding of AS to develop the applications of this instrument. BG is deeply indebted to The Max-Planck Gesellschaft for the funding of the Laplace Project, which funded an instrument as well as LTS, IM, and PKo who are pushing the boundaries of what APT can do. HZ and YC acknowledge support from the Chinese Scholarship Council. SKM and JH acknowledge support from the DFG/SFB TR 103 project A4. BG \& SKM are grateful to Steffen Neumeier, Malte Lenz, and Erdmann Spiecker for from FAU for the collaboration on the stacking faults in Cobased alloys. BG and TS acknowledge financial support from the DFG through the CorrKest project in collaboration with S. Siebentritt from U Luxembourg. SKM and AB are grateful for funding from the AvH Stifftung. PKü and EAJ acknowledge funding for the AProLAM project, funded jointly by the Fraunhofer Society and the Max Planck Society in their strategic cooperation framework. ZP is grateful for funding of the InitialWear project, funded by the Max-Planck-Gesellschaft (MPG) and the FraunhoferGesellschaft. A.K.S. is grateful to the Brazilian National Research Council (Conselho Nacional de Pesquisas, CNPQ) for the Ph.D. scholarship through the "Science without Borders" Project (203077/2014-8).

In terms of contributions to the writing of this article, BG wrote most of it, with direct input from some of the authors. DR is placed as last author because he is the Chef. Others helped prepare the figures. All the authors were given a chance to comment on the manuscript, comments that were mostly blended into the article or completely ignored by the first author. The rest of the authors are listed alphabetically to avoid any possible conflicts.

\section{REFERENCES}

1. E.W. Müller: Das Feldionenmikroskop. Z. Phys. 131, 136 (1951).

2. E.W. Müller: Field ion microscopy. Science 149, 591 (1965).

3. E.W. Müller: Resolution of the atomic structure of a metal surface by the field ion microscope. J. Appl. Phys. 27, 474 (1956). 
4. E.W. Müller, J.A. Panitz, S.B. McLane, and E.W. Müller: Atomprobe field ion microscope. Rev. Sci. Instrum. 39, 83 (1968).

5. D.G. Brandon, B. Ralph, S. Ranganathan, and M.S. Wald: Field ion microscope study of atomic configuration at grain boundaries. Acta Metall. 12, 813 (1964).

6. D.A. Smith, M.A. Fortes, A. Kelly, and B. Ralph: Contrast from stacking faults and partial dislocations in field-ion microscope. Philos. Mag. 17, 1065 (1968).

7. A.S. Berger, D.N. Seidman, and R.W. Balluffi: A quantitative study of vacancy defects in quenched platinum by field ion microscopy and electrical resistivity-I. Experimental results. Acta Metall. 21, 137 (1973).

8. M. Dagan, B. Gault, G.D.W. Smith, P.A.J. Bagot, and M.P. Moody: Automated atom-by-atom three-dimensional (3D) reconstruction of field ion microscopy data. Microsc. Microanal. 23, 1 (2017).

9. L. Beavan, R. Scanlan, and D. Seidman: The defect structure of depleted zones in irradiated tungsten. Acta Metall. 19, 1339 (1971).

10. F. Vurpillot, M. Gilbert, and B. Deconihout: Towards the threedimensional field ion microscope. Surf. Interface Anal. 39, 273 (2007).

11. M. Dagan, L.R. Hanna, A. Xu, S.G. Roberts, G.D.W. Smith, B. Gault, P.D. Edmondson, P.A.J. Bagot, and M.P. Moody: Imaging of radiation damage using complementary field ion microscopy and atom probe tomography. Ultramicroscopy 159, 387 (2015).

12. S. Katnagallu, M. Dagan, S. Parviainen, A. Nematollahi, B. Grabowski, P.A.J. Bagot, N. Rolland, J. Neugebauer, D. Raabe, F. Vurpillot, M.P. Moody, and B. Gault: Impact of local electrostatic field rearrangement on field ionization. J. Phys. D: Appl. Phys. 51, 105601 (2018).

13. F. Vurpillot, F. Danoix, M. Gilbert, S. Koelling, M. Dagan, and D.N. Seidman: True atomic-scale imaging in three dimensions: A review of the rebirth of field-ion microscopy. Microsc. Microanal. 23, 1 (2017).

14. D. Blavette, A. Bostel, J.M. Sarrau, B. Deconihout, and A. Menand: An atom probe for three-dimensional tomography. Nature 363, 432 (1993).

15. M.K. Miller: Atom Probe Tomography: Analysis at the Atomic Level (Kluwer Academic/Plenum Publishers, London, 2000).

16. B. Gault, M.P. Moody, J.M. Cairney, and S.P. Ringer: Atom Probe Microscopy (Springer, New York, New York, 2012).

17. T.F. Kelly, T.T. Gribb, J.D. Olson, R.L. Martens, J.D. Shepard, S.A. Wiener, T.C. Kunicki, R.M. Ulfig, D.R. Lenz, E.M. Strennen, E. Oltman, J.H. Bunton, and D.R. Strait: First data from a commercial local electrode atom probe (LEAP). Microsc. Microanal. 10, 373 (2004).

18. G. Da Costa, F. Vurpillot, A. Bostel, M. Bouet, and B. Deconihout: Design of a delay-line position-sensitive detector with improved performance. Rev. Sci. Instrum. 76, 13304 (2005)

19. O. Jagutzki, A. Cerezo, A. Czasch, R. Dorner, M. Hattass, M. Huang, V. Mergel, U. Spillmann, K. Ullmann-Pfleger, T. Weber, H. Schmidt-Bocking, and G.D.W. Smith: Multiple hit readout of a microchannel plate detector with a three-layer delayline anode. IEEE Trans. Nucl. Sci. 49, 2477 (2002).

20. B. Gault, M.P. Moody, F. de Geuser, D. Haley, L.T. Stephenson, and S.P. Ringer: Origin of the spatial resolution in atom probe microscopy. Appl. Phys. Lett. 95, 034103 (2009).

21. B. Gault, M.P. Moody, F. De Geuser, A. La Fontaine, L.T. Stephenson, D. Haley, and S.P. Ringer: Spatial resolution in atom probe tomography. Microsc. Microanal. 16, 99 (2010).

22. E. Cadel, F. Vurpillot, R. Larde, S. Duguay, and B. Deconihout: Depth resolution function of the laser assisted tomographic atom probe in the investigation of semiconductors. J. Appl. Phys. 106, 44908 (2009).
23. B. Gault, M. Müller, A. La Fontaine, M.P. Moody, A. Shariq, A. Cerezo, S.P. Ringer, and G.D.W. Smith: Influence of surface migration on the spatial resolution of pulsed laser atom probe tomography. J. Appl. Phys. 108, 044904 (2010).

24. M. Gruber, F. Vurpillot, A. Bostel, and B. Deconihout: A kinetic Monte Carlo approach on the influence of temperature. Surf. Sci. 605, 2025 (2011).

25. A.R. Waugh, E.D. Boyes, and M.J. Southon: Investigations of field evaporation with field desorption microscope. Surf. Sci. 61, 109 (1976).

26. F. Vurpillot and C. Oberdorfer: Modeling atom probe tomography: A review. Ultramicroscopy 159, 202 (2015).

27. B. Gault, M.P. Moody, J.M. Cairney, and S.P. Ringer: Atom probe crystallography. Mater. Today 15, 378 (2012).

28. V.J. Araullo-Peters, B. Gault, S.L. Shrestha, L. Yao, M.P. Moody, S.P. Ringer, and J.M. Cairney: Atom probe crystallography: Atomic-scale 3-D orientation mapping. Scr. Mater. 66, 907 (2012).

29. A.J. Breen, K. Babinsky, A.C. Day, K. Eder, C.J. Oakman, P.W. Trimby, S. Primig, J.M. Cairney, and S.P. Ringer: Correlating atom probe crystallographic measurements with transmission Kikuchi diffraction data. Microsc. Microanal. 23, 279-290 (2017)

30. L. Yao, M.P. Moody, J.M. Cairney, D. Haley, A.V. Ceguerra, C. Zhu, and S.P. Ringer: Crystallographic structural analysis in atom probe microscopy via $3 \mathrm{D}$ Hough transformation. Ultramicroscopy 111, 458 (2011).

31. V.J. Araullo-Peters, A.J. Breen, A.V. Ceguerra, B. Gault, S.P. Ringer, and J.M. Cairney: A new systematic framework for crystallographic analysis of atom probe data. Ultramicroscopy 154, 7 (2015).

32. M.P. Moody, B. Gault, L.T. Stephenson, D. Haley, and S.P. Ringer: Qualification of the tomographic reconstruction in atom probe by advanced spatial distribution map techniques Ultramicroscopy 109, 815 (2009).

33. M.P. Moody, F. Tang, B. Gault, S.P. Ringer, and J.M. Cairney: Atom probe crystallography: Characterization of grain boundary orientation relationships in nanocrystalline aluminium. Ultramicroscopy 111, 493 (2011).

34. D. Blavette, E. Cadel, A. Fraczkeiwicz, and A. Menand: Threedimensional atomic-scale imaging of impurity segregation to line defects. Science 286, 2317 (1999).

35. E. Cadel, A. Fraczkiewicz, and D. Blavette: Suzuki effect on $\{001\}$ stacking faults in boron-doped FeAl intermetallics. Scr. Mater. 51, 437 (2004).

36. Y. Li, D. Raabe, M. Herbig, P-P. Choi, S. Goto, A. Kostka, H. Yarita, C. Borchers, and R. Kirchheim: Segregation stabilizes nanocrystalline bulk steel with near theoretical strength. Phys. Rev. Lett. 113, 106104 (2014).

37. D. Blavette, A. Fraczkeiwicz, and E. Cadel: 3D atomic investigation of solute segregation to both planar and line defects in metallic alloys. J. Phys. IV 10, 111 (2000).

38. D. Blavette, E. Cadel, C. Pareige, B. Deconihout, and P. Caron: Phase transformation and segregation to lattice defects in Ni-base superalloys. Microsc. Microanal. 13, 464 (2007).

39. K. Thompson, P.L. Flaitz, P. Ronsheim, D.J. Larson, and T.F. Kelly: Imaging of arsenic Cottrell atmospheres around silicon defects by three-dimensional atom probe tomography. Science 317, 1370 (2007).

40. K. Hoummada, D. Mangelinck, B. Gault, and M. Cabié: Nickel segregation on dislocation loops in implanted silicon. Scr. Mater. 64, 378 (2011).

41. O. Cojocaru-Mirédin, T. Schwarz, and D. Abou-Ras: Assessment of elemental distributions at line and planar defects in $\mathrm{Cu}(\mathrm{In}, \mathrm{Ga})$ $\mathrm{Se}_{2}$ thin films by atom probe tomography. Scr. Mater. 148, 106114 (2018) 
42. O. Cojocaru-Miredin, E. Cadel, F. Vurpillot, D. Mangelinck, and D. Blavette: Three-dimensional atomic-scale imaging of boron clusters in implanted silicon. Scr. Mater. 60, 285 (2009).

43. K. Thompson, D. Lawrence, D.J. Larson, J.D. Olson, T.F. Kelly, and B. Gorman: In situ site-specific specimen preparation for atom probe tomography. Ultramicroscopy 107, 131 (2007).

44. R. Estivill, G. Audoit, J-P. Barnes, A. Grenier, and D. Blavette: Preparation and analysis of atom probe tips by xenon focused ion beam milling. Microsc. Microanal. 22, 576-582 (2016).

45. L. Reich, S.P. Ringer, and K. Hono: Origin of the initial rapid age hardening in an $\mathrm{Al}-1.7$ at.\% $\mathrm{Mg}-1.1$ at.\% Cu alloy. Philos. Mag. Lett. 79, 639 (1999).

46. S.P. Ringer and K. Hono: Microstructural evolution and age hardening in aluminium alloys: Atom probe field-ion microscopy and transmission electron microscopy studies. Mater. Charact. 44, 101 (2000).

47. M.L. Taheri, J.T. Sebastian, B.W. Reed, D.N. Seidman, and A.D. Rollett: Site-specific atomic scale analysis of solute segregation to a coincidence site lattice grain boundary. Ultramicroscopy 110, 278 (2010).

48. H. Aboulfadl, J. Deges, P. Choi, and D. Raabe: Dynamic strain aging studied at the atomic scale. Acta Mater. 86, 34 (2015).

49. D. Herzog, V. Seyda, E. Wycisk, and C. Emmelmann: Additive manufacturing of metals. Acta Mater. 117, 371 (2016).

50. T. DebRoy, H.L. Wei, J.S. Zuback, T. Mukherjee, J.W. Elmer, J.O. Milewski, A.M. Beese, A. Wilson-Heid, A. De, and W. Zhang: Additive manufacturing of metallic componentsProcess, structure and properties. Prog. Mater. Sci. 92, 112 (2018).

51. Y. Harada and D.C. Dunand: Thermal expansion of $\mathrm{Al}_{3} \mathrm{Sc}$ and $\mathrm{Al}_{3}\left(\mathrm{Sc}_{0.75} \mathrm{X}_{0.25}\right)$. Scr. Mater. 48, 219 (2003).

52. F. Tang, D.S. Gianola, M.P. Moody, K.J. Hemker, and J.M. Cairney: Observations of grain boundary impurities in nanocrystalline $\mathrm{Al}$ and their influence on microstructural stability and mechanical behaviour. Acta Mater. 60, 1038 (2012).

53. P. Kontis, Z. Li, D.M. Collins, J. Cormier, D. Raabe, and B. Gault: The effect of chromium and cobalt segregation at dislocations on nickel-based superalloys. Scr. Mater. 145, 76 (2018).

54. P. Kontis, D.M. Collins, A.J. Wilkinson, R.C. Reed, D. Raabe, and B. Gault: Microstructural degradation of polycrystalline superalloys from oxidized carbides and implications on crack initiation. Scr. Mater. 147, 59 (2018).

55. S.K. Makineni, M. Lenz, P. Kontis, Z. Li, A. Kumar, P.J. Felfer, S. Neumeier, M. Herbig, E. Spiecker, D. Raabe, and B. Gault: Correlative microscopy-Novel methods and their applications to explore 3D chemistry and structure of nanoscale lattice defects: A case study in superalloys. JOM 70, 1736 (2018).

56. M. Kuzmina, M. Herbig, D. Ponge, S. Sandlobes, and D. Raabe: Linear complexions: Confined chemical and structural states at dislocations. Science 349, 1080 (2015).

57. G. Love: Dislocation pipe diffusion. Acta Metall. 12, 731 (1964).

58. M. Legros, G. Dehm, E. Arzt, and T.J. Balk: Observation of giant diffusivity along dislocation cores. Science 319, 1646 (2008).

59. M. Kolbe, A. Dlouhy, and G. Eggeler: Dislocation reactions at $\gamma / \gamma^{\prime}$-interfaces during shear creep deformation in the macroscopic crystallographic shear system (001)[110] of CMSX6 superalloy single crystals at $1025^{\circ}$ C. Mater. Sci. Eng., A 246, 133 (1998).

60. T.M. Pollock and A.S. Argon: Directional coarsening in nickelbase single crystals with volume fractions of coherent precipitates. Acta Metall. Mater. 42, 1859 (1994).

61. R.C. Reed: The Superalloys: Fundamentals and Applications (Cambridge University Press, New York, New York, 2006).

62. T. Connolley, P.A.S. Reed, and M.J. Starink: Short crack initiation and growth at $600{ }^{\circ} \mathrm{C}$ in notched specimens of Inconel718. Mater. Sci. Eng., A 340, 139 (2003).
63. M.S. Titus, A. Mottura, G. Babu Viswanathan, A. Suzuki, M.J. Mills, and T.M. Pollock: High resolution energy dispersive spectroscopy mapping of planar defects in $\mathrm{L}_{2}$-containing Co-base superalloys. Acta Mater. 89, 423 (2015).

64. Y. Eggeler, J. Müller, M.S. Titus, A. Suzuki, T.M. Pollock, and E. Spiecker: Planar defect formation in the $\gamma^{\prime}$ phase during high temperature creep in single crystal CoNi-base superalloys. Acta Mater. 113, 335 (2016).

65. S. Zaefferer and N-N. Elhami: Theory and application of electron channelling contrast imaging under controlled diffraction conditions. Acta Mater. 75, 20 (2014).

66. S.K. Makineni, A. Kumar, M. Lenz, P. Kontis, T. Meiners, S. Zaefferer, C.H. Zenk, G. Eggeler, S. Neumeier, E. Spiecker, D. Raabe, and B. Gault: A new diffusive phase transformation mechanism assisted by extended dislocations during creep of a single crystalline CoNi based superalloy. Acta Mater. 155, 362 (2018).

67. S.K. Makineni, M. Lenz, S. Neumeier, E. Spiecker, D. Raabe, and B. Gault: Elemental segregation to antiphase boundaries in a crept CoNi-based single crystal superalloy. Scr. Mater. 157, 62 (2018).

68. T. Kato: $\mathrm{Cu}(\mathrm{In}, \mathrm{Ga})(\mathrm{Se}, \mathrm{S})_{2}$ solar cell research in Solar Frontier: Progress and current status. Jpn. J. Appl. Phys. 56, 04CA02 (2017).

69. T. Schwarz, G. Stechmann, B. Gault, O. Cojocaru-Mirédin, R. Wuerz, and D. Raabe: Correlative transmission Kikuchi diffraction and atom probe tomography study of $\mathrm{Cu}(\mathrm{In}, \mathrm{Ga}) \mathrm{Se}_{2}$ grain boundaries. Prog. Photovoltaics Res. Appl. 26, 196 (2018).

70. D. Abou-Ras, S.S. Schmidt, N. Schäfer, J. Kavalakkatt, T. Rissom, T. Unold, R. Mainz, A. Weber, T. Kirchartz, E. Simsek Sanli, P.A. van Aken, Q.M. Ramasse, H-J. Kleebe, D. Azulay, I. Balberg, O. Millo, O. Cojocaru-Mirédin, D. Barragan-Yani, K. Albe, J. Haarstrich, and C. Ronning: Compositional and electrical properties of line and planar defects in $\mathrm{Cu}(\mathrm{In}, \mathrm{Ga}) \mathrm{Se}_{2}$ thin films for solar cells-A review. Phys. Status Solidi RRL 10, 363 (2016).

71. S-H. Wei, S.B. Zhang, and A. Zunger: Effects of $\mathrm{Na}$ on the electrical and structural properties of $\mathrm{CuInSe}_{2}$. J. Appl. Phys. 85, 7214 (1999).

72. A. Kwiatkowski da Silva, D. Ponge, Z. Peng, G. Inden, Y. Lu, A. Breen, B. Gault, and D. Raabe: Phase nucleation through confined spinodal fluctuations at crystal defects evidenced in $\mathrm{Fe}-$ Mn alloys. Nat. Commun. 9, 1137 (2018).

73. A. Kwiatkowski da Silva, G. Leyson, M. Kuzmina, D. Ponge, M. Herbig, S. Sandlöbes, B. Gault, J. Neugebauer, and D. Raabe: Confined chemical and structural states at dislocations in $\mathrm{Fe}-$ 9 wt $\%$ Mn steels: A correlative TEM-atom probe study combined with multiscale modelling. Acta Mater. 124, 305 (2017).

74. P.R. Cantwell, M. Tang, S.J. Dillon, J. Luo, G.S. Rohrer, and M.P. Harmer: Grain boundary complexions. Acta Mater. 62, 1 (2014).

75. T.J. Rupert: The role of complexions in metallic nano-grain stability and deformation. Curr. Opin. Solid State Mater. Sci. 20, 257 (2016).

76. M. Kuzmina, D. Ponge, and D. Raabe: Grain boundary segregation engineering and austenite reversion turn embrittlement into toughness: Example of a 9 wt $\%$ medium Mn steel. Acta Mater. 86, 182 (2015).

77. H. Numakura and M. Koiwa: Hydride precipitation in titanium. Acta Metall. 32, 1799 (1984).

78. C. Briant, Z. Wang, and N. Chollocoop: Hydrogen embrittlement of commercial purity titanium. Corros. Sci. 44, 1875 (2002).

79. H.G. Nelson: A film-rupture model of hydrogen-induced, slow crack growth in acicular alpha-beta titanium. Metall. Trans. A $\mathbf{7}$, 621 (1976). 
80. L.M. Gammon, R.D. Briggs, J.M. Packard, K.W. Batson, R. Boyer, and C.W. Domby: Metallography and microstructures of titanium and its alloys. Mater. Park. OH ASM Int. 9, 899 (2004).

81. R. Ding and I.P. Jones: In situ hydride formation in titanium during focused ion milling. J. Electron Microsc. 60, 1 (2011).
82. Y. Chang, A.J. Breen, Z. Tarzimoghadam, P. Kürnsteiner, H. Gardner, A. Ackerman, A. Radecka, P.A.J. Bagot, W. Lu, T. Li, E.A. Jägle, M. Herbig, L.T. Stephenson, M.P. Moody, D. Rugg, D. Dye, D. Ponge, D. Raabe, and B. Gault: Characterizing solute hydrogen and hydrides in pure and alloyed titanium at the atomic scale. Acta Mater. 150, 273 (2018). 